\title{
Multidrug-resistant Acinetobacter Iwoffii infection in neonatal intensive care units
}

This article was published in the following Dove Press journal:

Research and Reports in Neonatology

7 January 201 I

Number of times this article has been viewed

\author{
Narongsak Nakwan ${ }^{1,2}$ \\ Jeerawan Wannaro ${ }^{2}$ \\ Narongwit Nakwan ${ }^{3}$ \\ 'Neonatal Intensive Care Unit, \\ ${ }^{2}$ Department of Pediatrics, \\ ${ }^{3}$ Department of Medicine, Hat Yai \\ Medical Education Center, Hat Yai \\ Hospital, Songkhla, Thailand
}

Correspondence: Narongsak Nakwan Neonatal Intensive Care Unit, Department of Pediatrics, Hat Yai Medical Education Center, Hat Yai Hospital, Songkhla, 90 I I0, Thailand Tel +668 I 8984566

Fax +66 74273 I6I

Emailnnakwan@hotmail.com
Aim: To describe the clinical, bacteriological features, and outcome of Acinetobacter lwoffii infection in the neonatal population.

Method: We retrospectively reviewed the medical records of four neonatal cases of $A$. lwoffii infection admitted to the Hat Yai Hospital, January 2005 to December 2009.

Results: Four cases (one in 2007, and three in 2008) were identified as having $A$. lwoffii infection. Of the four cases, three presented with late-onset infection (after 72 hours of age), while 1 presented with early-onset (within the first 72 hours of age). All cases were inserted with umbilical catheters, required positive pressure mechanical ventilation, and had been treated previously with antibiotic drugs at time of diagnosis. Antimicrobial susceptibility testing of seven isolates (three in blood, three in sputum, and one in cerebrospinal fluid) was performed using the disk diffusion method. The most tested isolates were susceptible to netilmicin, imipenem, cefoperazone/sulbactam, while most were simultaneously generally resistant to amikacin, gentamicin, ceftazidime, ceftriaxone, cefepime, ciprofloxacin, and clindamicin. The treatment of $A$. lwoffii infection in the four cases varied. Only one case was successfully treated with imipenem, while three cases died from severe ventilator-associated pneumonia, and severe sepsis.

Conclusion: This study increases awareness of $A$. lwoffii infection in the neonatal population, particularly in premature infants with several risk factors for nosocomial infection, including central intravascular catheters and prolonged mechanical ventilation.

Keywords: Acinetobacter lwoffi, Acinetobacter infection, newborn infant

\section{Introduction}

Acinetobacter organisms are widespread, and relatively harmless organisms with the ability to persist in the hospital environment for prolonged periods. ${ }^{1}$ Most nosocomial Acinetobacter infections in neonatal intensive care units (NICU) have been attributed to $A$. baumannii, which can cause pneumonia, meningitis, and sepsis. ${ }^{2}$ But the clinical effect of other Acinetobacter species, especially A. lwoffii (formerly known as Mima polymorpha, A. calcoaceticus var. lwoffii), has rarely been reported in the neonatal population. $^{3}$

During 2008, there was small outbreak of $A$. lwoffii infection in three infants in our NICU, with high mortality. Isolation of this organism requires careful clinical evaluation to determine the significance of the finding. In this report, we describe the clinical features and presentations, laboratory diagnosis, treatments, and outcomes of these infections in our NICU. submit your manuscript $\mid$ www.dovepress.com

Dovepress

DOI: 10.2147/RRN.S15964
Research and Reports in Neonatology 20 I I:I I-4

(C) 20I I Nakwan et al, publisher and licensee Dove Medical Press Ltd. This is an Open Access article which permits unrestricted noncommercial use, provided the original work is properly cited. 


\section{Materials and methods}

\section{Study design and patient population}

The cases of $A$. lwoffii infection admitted to the NICU, Department of Pediatrics, Hat Yai Hospital, a tertiary-care hospital in southern Thailand, were retrospectively identified from a computerized database of the Department of Microbiology, Hat Yai Hospital from January 2005 through to December 2009. The NICU of Hat Yai Hospital is a facility for hospital-born neonates and a referral center for several hospitals in the vicinity. It consists of a 30-bed unit and includes 12 intensive care and six intermediate care beds located in one large room and an additional recovery unit consisting of 12 beds. A neonatology team consisting of experienced neonatologists or pediatricians, one to two pediatric residents, and neonatology nurses cared for the neonates.

\section{Data collection}

We collected data on the basic characteristics, clinical and laboratory information, and the sensitivity profile of the isolates, treatment, and outcomes. The criterion for inclusion in this study was the isolation of $A$. lwoffii in sterile body fluid from at least one culture, including blood or cerebrospinal fluid, and, if in an intubated neonate, a tracheal aspirate.

\section{Microbiology and antimicrobial susceptibility test}

Blood samples were obtained using BacT/Alert FA bottles (bioMérieux, Durham, NC) and specimens were inoculated with an automated BacT/Alert system (bioMérieux, Marcy l'Etoile, France). Sputum specimens were obtained according to standard bacteriological techniques, and were then plated onto blood agar plates, chocolate agar plates, and MacConkey agar plates. They were incubated at $35^{\circ} \mathrm{C}$ and examined for growth at 24 hours. A. lwoffii organisms were identified by biochemical analysis with cytochrome oxidase (negative), oxidative/fermentative glucose (negative), nitrate reduction (negative), and citrate (negative). Routine laboratory susceptibility testing procedures of $A$. lwoffii isolates for commonly used antibiotics were performed with the use of the Kirby-Bauer disk-diffusion method, as recommended by the Clinical and Laboratory Standards Institute (CLSI) guidelines.

\section{Environmental surveillance}

Environmental cultures surveys were performed in August, 2008. Multiple samples were obtained for cultures, with particular emphasis on humid places, mechanical ventilators and their humidifier boxes, infant incubators, medical charts, tops of trolleys, sinks, nurse counters, radiant warmers, tourniquet rubbers, and hands of heath-care workers. Environmental and clinical cultures were performed by standard method.

\section{Results}

During the study period, there were 35,352 live-birth infant deliveries at this institute with an annual average of 7,070 live births, and 3,319 infants admitted to NICU with an annual average number admitted of 664 infants and an average length of stay of 13 days. From the 3,319 infants, 4,958 blood cultures were performed; of these, 205 were positive with a rate of $4 \%$. Of the 205 specimens, 17 were positive for $A$. baumannii, only three blood cultures were positive for $A$. lwoffii.

From the medical database, only four cases (one case in 2007, and three cases in 2008) were identified as having A. lwoffii infection with an incidence of 0.1 per 1,000 livebirths. A summary of basic characteristics data, clinical and laboratory information, treatment, and outcomes are presented in Table 1. Of the four cases, three presented with late-onset of infection (after 72 hours of age), while one presented with early-onset (within the first 72 hours of age). All cases were inserted with umbilical catheters, required positive pressure mechanical ventilation, and had been treated previously with antibiotic drugs at time of diagnosis. The signs and symptoms at the time of diagnosis were typical for neonatal sepsis, and nonspecific findings that were present included fever, hypothermia, apnea, lethargy, anemia, or seizures.

Antimicrobial susceptibility testing of seven isolates (three in blood, three in sputum, and one in cerebrospinal fluid) was performed using the disk diffusion method. Of the seven isolates, one was identified from sputum in 2007 and the other six isolates were identified in 2008. Because of a small outbreak in three patients in 2008, six isolates were summarized in one strain. The antibiotic susceptibility test therefore indicated only two strains, with all susceptible to netilmicin, imipenem, cefoperazone/sulbactam, while both were simultaneously generally resistant to amikacin, gentamicin, ceftazidime, ceftriaxone, cefepime, and ciprofloxacin, clindamicin. The treatment of $A$. lwoffii infection in the four cases varied (Table 1). Only one case (case 2) was successfully treated with imipenem, while three cases died from severe ventilator-associated pneumonia (case 1) and severe sepsis (cases 3 and 4).

\section{Environmental investigation}

Of the 20 specimen cultures, 32 isolates were identified, including Bacillus spp. (18), Escherichia coli (3), A. baumannii 
Table I Clinical and laboratory characteristics of A. Iwoffii infection in 4 neonates

\begin{tabular}{|c|c|c|c|c|}
\hline & Case I & Case 2 & Case 3 & Case 4 \\
\hline Date of birth & April I8, 2007 & February 2, 2008 & February 9, 2008 & February I8, 2008 \\
\hline Gestational age (weeks) & 34 & 40 & 28 & 28 \\
\hline Sex & Female & Female & Male & Male \\
\hline Birth weight (g) & 1,980 & 2,770 & 1,290 & 880 \\
\hline Underlying diseases & $\mathrm{CHD}$ & MAS, PPHN & RDS & RDS \\
\hline Prior antibiotic drugs ( $\times$ duration) & $\begin{array}{l}\text { Ampicillin and gentamicin } \times \\
6 \text { days } \rightarrow \text { cefoperazone/ } \\
\text { sulbactam } \times 17 \text { days }\end{array}$ & $\begin{array}{l}\text { Ampicillin and gentamicin } \times \\
2 \text { days } \rightarrow \text { cetazidime and } \\
\text { amikacin } \times 2 \text { days }\end{array}$ & $\begin{array}{l}\text { Ampicillin and } \\
\text { gentamicin } \times 8 \text { days }\end{array}$ & $\begin{array}{l}\text { Ampicillin and } \\
\text { gentamicin } \times 3 \text { days }\end{array}$ \\
\hline Prior central line/duration (days) & Yes/14 & Yes/II & Yes/8 & Yes/3 \\
\hline Prior ventilator/duration (days) & Yes/20 & Yes/II & Yes/8 & Yes/3 \\
\hline Age of infection onset (days) & 20 & II & 8 & 3 \\
\hline Symptoms & Fever, lethargy & Lethargy, fever & $\begin{array}{l}\text { Apnea, seizure, } \\
\text { anemia }\end{array}$ & $\begin{array}{l}\text { Apnea, lethargy, } \\
\text { hypothermia }\end{array}$ \\
\hline White blood cells (cells $/ \mathrm{mm}^{3}$ ) & 13,700 & 28,500 & 8,000 & 14,200 \\
\hline Platelets count (cells $/ \mathrm{mm}^{3}$ ) & 140,000 & 342,000 & 130,000 & 134,000 \\
\hline Hemoglobin (gm/dL)/hematocrit (\%) & $14.2 / 43$ & $11.6 / 34$ & $9.7 / 28$ & $14.2 / 37$ \\
\hline Blood culture & Neg & Neg & Pos & Pos \\
\hline CSF culture & Neg & Neg & Pos & NA \\
\hline Sputum/urine cultures & Pos/NA & Pos/Neg & NA/NA & Pos/NA \\
\hline Clinical diagnosis (date of diagnosis) & VAP & VAP & $\begin{array}{l}\text { Bacteremia, } \\
\text { meningitis }\end{array}$ & Bacteremia, VAP \\
\hline $\begin{array}{l}\text { Antibiotic drugs ( } \times \text { duration of } \\
\text { treatment) }\end{array}$ & $\begin{array}{l}\text { Ceftazidime and } \\
\text { amikacin } \times 14 \text { days }\end{array}$ & Imipenem $\times 14$ days & $\begin{array}{l}\text { Ceftazidime and } \\
\text { amikacin } \times 3 \text { days } \\
\rightarrow \text { meropenem } \times \\
5 \text { days }\end{array}$ & $\begin{array}{l}\text { cefoperazone/ } \\
\text { sulbactam and } \\
\text { metronidazole } \times \text { I day }\end{array}$ \\
\hline Central line removal & Yes & No & No & No \\
\hline Outcome & Died & Survived & Died & Died \\
\hline
\end{tabular}

Abbreviations: CSF, cerebrospinal fluid; CHD, cyanotic heart disease; MAS, meconium aspiration syndrome; NA, not available; Neg, negative; PPHN, persistent hypertension of the newborn; Pos, positive; RDS, respiratory distress syndrome; VAP, ventilator-associated pneumonia.

(3), Enterococcus spp. (3), Enterobacter aerogenes (2), Pseudomonas stutzeri (1), Enterobacter cloacae (1), and coagulase-negative Staphylococcus (1). A. lwoffii was not isolated from environmental investigation.

\section{Discussion}

The clinical features at the onset of $A$. lwoffii infection in neonates appeared to be no different from neonates presenting with infections caused by other bacterial organisms. The risk factors for $A$. lwoffii infection in our cases might be prematurity, prolonged mechanical ventilation, and indwelling central intravascular catheters because all of these factors were present in our patients. Prematurity may be associated with occurring disseminated disease which may reflect the neonates' immature immune system, ${ }^{4}$ while central intravascular catheterization has been previously reported as carrying risk of infection in adult patients. ${ }^{5}$ Our study found that all seven isolates were multidrug-resistant strains, defined as isolates resistant to $\geq 3$ classes of drugs. Therefore this study suggests that carbapenem with or without netilmicin should be the first-line drug treatment of $A$. lwoffii infection in neonates; however, treatment may depend on the susceptibility of the organisms of each hospital. Interestingly, the cluster outbreak of $A$. lwoffii infection may explain the mode of infection in three of our cases (cases 2, 3, and 4) because these patients were infected at the same time and had a similar pattern of organism susceptibility (data not shown). Epidemiologic investigation of the outbreak, such as molecular genetic analysis of organisms, could be done to assess the origin of the infection. Unfortunately, this analysis is not available in our hospital. However, we did investigate the environment to identify the source and mode of transmission during the outbreak. Furthermore, we reviewed standard infection control measures, especially hand-washing practices and proper cleaning and disinfecting of medical equipment, because it has been described previously that $A$. lwoffii has been detected in environmental sources, particularly on the hands of nursing staff. ${ }^{6}$ The results of environmental cultures showed that $A$. lwoffii could not be detected in our unit at the time of outbreak. In the 10 months since this cluster outbreak, there has been no further $A$. lwoffii infection in our unit. 
Our study has several limitations. Because of its retrospective nature, we lacked important molecular genetic information of the organisms to assess the origin of the infection, and the environmental investigations were partially performed after the outbreak. Therefore, the cause of this epidemic cannot be proved with certainly. In addition, the identify of $A$. lwoffii isolates was only performed by biochemical analysis because genotypic identification is not available in our hospital. Lastly, this small sample size reflects the limitation of the treatment strategy and risk factors of $A$. lwoffii infection development.

This report provides clinical and laboratory information of $A$. lwoffii infection in neonates and confirms that the background rate of infection with $A$. lwoffii is low. In addition, our study increases awareness of $A$. lwoffii infection in the neonatal population, particularly in premature infants with several risk factors for nosocomial infection, including central intravascular catheters and prolonged mechanical ventilation.

\section{Acknowledgments}

We thank the pediatric staff, pediatric residents, and nurses for caring for the patients, and also thank Ms Jude Hall for editing the manuscript.

\section{Disclosure}

No conflicts of interest were declared in relation to this paper.

\section{References}

1. Bergogne-Berezin E, Towner KJ. Acinetobacter spp. as nosocomial pathogens: microbiological, clinical, and epidemiological features. Clin Microbiol Rev. 1996;9(2):148-165.

2. Huang YC, Su LH, Wu TL, et al. Outbreak of Acinetobacter baumannii bacteremia in a neonatal intensive care unit: clinical implications and genotyping analysis. Pediatr Infect Dis J. 2002;21(12):1105-1109.

3. Chotigeat U, Khorana M, Waranawat N. Successful treatment of late onset infection due to multi-drug resistant Acinetobacter lwoffii in a low birth weight neonate using ciprofloxacin. J Med Assoc Thai. 2001;84(6): 910-913.

4. Bellanti JA, Zeligs BJ, Pung YH. Immunology of the fetus and newborn. In: MacDonald MG, Seshia MMK, Mullett MD, eds. Avery's Neonatology: Pathophysiology \& management of the newborn. 6th ed. Philadelphia, PA: Lippincott William \& Wilkins. 2005:1135-1161.

5. Seifert H, Strate A, Schulze A, Pulverer G, et al. Vascular catheter-related bloodstream infection due to Acinetobacter johnsonii (formly Acinetobacter calcoaceticus var. lwoffii): report of 13 cases. Clin Infect Dis. 1993;17(4): 632-636.

6. Larson EL, Cimiotti JP, Haas J, et al. Gram-negative bacilli associated with catheter-associated and non-catheter-associated bloodstream infections and hand carriage by healthcare workers in neonatal intensive care units. Pediatr Crit Care Med. 2005;6(4):457-461.
Research and Reports in Neonatology

\section{Publish your work in this journal}

Research and Reports in Neonatology is an international, peer-reviewed, open access journal publishing publishing original research, reports, editorials, reviews and commentaries on neonatal health. The manuscript management system is completely online and includes a very quick and
Dovepress

fair peer-review system. Visit to read real quotes from published authors. 